\title{
El procedimiento restringido en la nueva Ley 9/2017, de Contratos del Sector Público
}

Francisco Delgado Piqueras

DOI: https://doi.org/10.47623/ivap-rvap.110.2018.1.03

\begin{abstract}
Sumario: I. Antecedentes. -II. Características generales. -III. Las solicitudes de participación: 1. Plazo de presentación. 2. Documentación a adjuntar.-IV. Selección de los candidatos: 1. Criterios objetivos de solvencia 2. Número de empresarios a invitar. 3. Examen e invitación de los candidatos. -V. Contenido de la invitación. -VI. Plazo de presentación de proposiciones.-VII. Adjudicación.-VIII. Bibliografía citada.
\end{abstract}

\section{Antecedentes}

La reciente aprobación de la Ley 9/2017, de 8 de noviembre, de Contratos del Sector Público, "por la que se transponen al ordenamiento jurídico español las Directivas del Parlamento Europeo y del Consejo 2014/23/ UE y 2014/24/UE, de 26 de febrero de 2014» (en adelante LCSP) a buen seguro va a provocar ríos de tinta, pues no en vano es una reforma de gran repercusión para las Administraciones Públicas y demás entidades del llamado sector público y para las empresas privadas contratistas. Amén de su trascendencia jurídica, es obvio resaltar que afecta a todo un sector económico de enormes magnitudes. De hecho, los primeros comentarios por parte de autores mañaneros han empezado a presentar sus mayores virtudes y también sus carencias(1). El presente trabajo tiene un objetivo menos ambicioso, pues no vamos a entrar en las Directivas propiamente

(1) Aun antes de aparecer en el BOE, el profesor GIMENO FELIU, J.M. ${ }^{\text {a }}$ (2017) nos introduce en las grandes y positivas novedades de la reforma: "La nueva Ley de Contratos del Sector Público: una ventana de oportunidad para recuperar el liderazgo institucional público con y desde la contratación pública», Observatorio de Contratación Pública, consulta 23-10-2017 (http://www.obcp.es/index.php/ mod.opiniones/mem.detalle/id.317/relmenu.3/chk.5ae6d56c8ce0a3e6533497d25a4135ff). Por su parte, el profesor GONZALEZ GARCIA, J. (2017) critica las oportunidades perdidas en: "Nueva Ley de Contratos del Sector Público", consulta 4-11-2017 (https://www.globalpoliticsandlaw.com/2017/11/04/ nueva-ley-contratos-sector-publico/). 
dichas (2) y solo pretendemos examinar una parte pequeña de la LCSP, con el fin de conocer su alcance para el procedimiento restringido, es decir, desentrañar qué permanece de su anterior regulación y cuáles pueden ser las novedades, tampoco muchas, pero que en todo caso conviene ir conociendo. Quiere contribuir así a la tarea ingente de desgranar una ley que tiene una desmedida extensión y no pequeña complejidad, si cabe aun mayor que sus antecesoras. Por razones obvias, todavía no hay jurisprudencia que aplique la nueva Ley, pero sí pueden ilustrarnos «mutatis mutandi» las sentencias dictadas al hilo de la legislación precedente, aunque tampoco son muchas y casi siempre van a la solución del caso (3).

La esencia del procedimiento restringido es que solo pueden presentar proposiciones $u$ ofertas los empresarios previamente seleccionados por la Administración Pública, los cuales van a ser escogidos a través de una convocatoria pública. Por tanto, se desarrolla en dos fases, una pública y abierta a cualesquiera empresas que puedan estar interesadas y cumplan unos determinados requisitos subjetivos, destinada a seleccionar un número limitado de ofertantes a los que se va a invitar a formular sus proposiciones concretas. La segunda fase consistirá en elegir la oferta objetivamente mejor de entre las presentadas por las invitadas.

Huelga decir que los principios generales de igualdad, transparencia y libre competencia rigen también en el procedimiento restringido, por lo que los órganos de contratación han de dar a los licitadores y candidatos un tratamiento igualitario y no discriminatorio (4). No puede limi-

(2) De lo mucho escrito al respecto, por todos, véase el trabajo de mi compañera l. GALLEGO CÓRCOLES: «La modificación de los contratos en la cuarta generación de directivas sobre contratación pública», presentado en el X Congreso de la AEPDA, cuyas Actas fueron publicadas por AranzadiThomson, 2015.

(3) Aunque sus resoluciones no son fuente del Derecho y excedería los márgenes de este trabajo, por su "autoritas" sí merecería un estudio sistemático la doctrina procedente del Tribunal Administrativo Central de Recursos Contractuales y sus análogos autonómicos, cuyo carácter cuasi-jurisdiccional ha sido reconocido por el TJUE, v. gr. para plantearle la cuestión prejudicial. Véase M. ${ }^{a}$ José SANTIAGO FERNÁNDEZ, "Los Tribunales administrativos de recursos contractuales como mecanismos de control en la contratación pública. Perspectiva actual y de futuro", en http://asocex.es/lostribunales-administrativos-de-recursos-contractuales-como-mecanismos-de-control-en-la-contratacion-publica-perspectiva-actual-y-de-futuro; J. C. ROMAR VILLAR, "Diferencias en la doctrina de los tribunales administrativos de recursos contractuales, en relación al recurso especial en materia de contratación", 20-1-2014, http://www.obcp.es/index.php/mod.opiniones/mem.detalle/id.132/relcategoria.121/relmenu.3/chk.d269a259dba4a3fd84b08962cde4337b

(4) Así lo destaca, entre otras, la STJCE (Sala Sexta) de 12 de diciembre de 2002, en el asunto C-470/99, en una cuestión prejudicial elevada por un tribunal austriaco, a propósito un procedimiento de adjudicación de un contrato público de obras: «Resulta de lo anterior, que el procedimiento de adjudicación de un contrato público debe respetar, en todas sus fases, en particular en la de selección de los candidatos en un procedimiento restringido, tanto el principio de igualdad de trato de los posibles licitadores como el de transparencia, para que todos los licitadores dispongan de las mismas oportunidades al formular el contenido de sus solicitudes de participación o de sus ofertas" 
tarse la participación por la norma jurídica o el ánimo de lucro en la contratación, salvo en los contratos reservados para Centros Especiales de Empleo de iniciativa social y a empresas de inserción (DA 4. ${ }^{a}$ LCSP). EI procedimiento restringido no persigue eludir los requisitos de publicidad ni restringir artificialmente la competencia favoreciendo o perjudicando indebidamente a determinados empresarios. En puridad, el procedimiento restringido interesa por igual a las empresas como a la Administración, puesto que evita a las primeras incurrir en innecesarios costes de preparación de la proposición y a la segunda el coste de su tramitación y valoración.

Un procedimiento de adjudicación en el que hubiera un filtro de los ofertantes, para examinar solo las ofertas de algunos elegidos por haber acreditado el cumplimiento de unos requisitos de solvencia económica, financiera, técnica o profesional ha tenido presencia en la legislación española al menos desde el Reglamento de Contratación de las Corporaciones Locales, aprobado por Decreto de 9 de enero de 1953(5), luego trasplantado a la Ley de Contratos del Estado de 1965 y su Reglamento ejecutivo (6). Sin embargo, hay que recordar que el procedimiento res-

(véase, en este sentido, por lo que se refiere a la fase de comparación de ofertas, la sentencia de 25 de abril de 1996, Comisión/Bélgica, C-87/94, Rec. p. I-2043, apartado 54).

Una lectura actualizada de estos principios, en el trabajo de GIMENO FELIU, J.M. (2015), "La reforma comunitaria en materia de contratos públicos y su incidencia en la legislación española. Una visión desde la perspectiva de la integridad", en libro Observatorio de los Contratos Públicos, número especial 2015, Las Directivas de Contratación Pública, Aranzadi, Cizur Menor (Navarra), que recoge la ponencia presentada por el profesor en el X Congreso de la AEPDA.

(5) CARBONERO GALLARDO, J.M., (2010), "La adjudicación de los contratos públicos», en La Ley، pág. 135, nos ilustra sobre este antecedente: el concurso-subasta del art. 39 RCCL; las críticas y las opiniones favorables de diversos autores, entre ellos GARCÍA DE ENTERRÍA, E. (1953), "Dos regulaciones orgánicas de la contratación administrativa», en RAP n. ${ }^{\circ}$ 10, pág. 254: "Una importante aportación de la legislación local que no ha hecho más que desarrollar el Reglamento de 9 de enero último, es la consagración del sistema llamado de concurso-subasta, que no es más que un procedimiento de selección previa de licitadores para limitar entre ellos la subasta según la mejor postura económica, fórmula técnica verdaderamente progresiva, regulada además en el nuevo Reglamento con un positivo acierto. Las exigencias de garantía técnica de los constructores quedan perfectamente a cubierto, en contra de lo que ocurre en la subasta ordinaria; a la vez la depuración objetiva del precio a través de la licitación por la mejor postura económica se asegura igualmente, conservando, por tanto, las ventajas clásicas de la subasta y sorteando los inconveniente" del concurso simple, en que tantas veces es forzoso valorar sobre un único plano los factores heterogéneos de baratura, garantías técnicas, etc. Nada más oportuno que trasplantar el sistema a la regulación de los contratos de la Administración central, y nada más fácil.»

(6) El profesor MORENO MOLINA, J.A. señala su equivalencia con la fase de admisión previa de los procedimientos de concurso y subasta para la adjudicación de obras; MORENO MOLINA, J.A. y

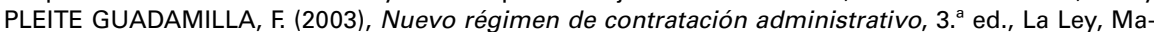
drid, pág. 409. Véase arts. 34 y 35 del Decreto 923/1965, de 8 de abril, por el que se aprueba el texto articulado de la Ley de Contratos del Estado, desarrollado en los arts. 93 y 110 a 112 al Reglamento de Contratos del Estado (Decreto 3410/1975, de 25 de noviembre). Bajo este procedimiento, en síntesis, las empresas interesadas tenían que remitir los documentos justificativos del cumplimiento de unos criterios objetivos, en virtud de los cuales algunas pasarían a ser admitidas a la posterior subasta o concurso. 
tringido como tal fue introducido por el Real Decreto Legislativo 931/1986, de 2 de mayo, "por el que se modifica la Ley de Contratos del Estado para adaptarla a las directivas de la Comunidad Económica Europea» (nuevo art. 36 bis), limitándolo a los de una cuantía igual o superior a un millón de unidades de cuenta europea. Sin entrar en el detalle, es claro que su evolución ha seguido el paso marcado por las Directivas europeas.

El siguiente hito lo marcan los arts. 74 (Procedimientos de adjudicación) y 92 (Normas para la aplicación del procedimiento restringido) de la Ley 13/1995, de 18 de mayo, "de Contratos de las Administraciones Públicas", que pasan a ser sin modificaciones sustantivas los arts. 73 y 92 del Real Decreto Legislativo 2/2000, de 16 de junio, "por el que se aprueba el texto refundido de la Ley de Contratos de las Administraciones Públicas». Siguiendo las Directivas, esta Ley estructuraba tres procedimientos de adjudicación: abierto, restringido y negociado. Mientras que el procedimiento negociado únicamente podía seguirse en los casos expresamente previstos por la Ley, la utilización de los procedimientos abierto y restringido era libre para el órgano de contratación, que podía optar igualmente por la subasta o el concurso como forma de adjudicación (art 75). El procedimiento restringido seguía el procedimiento general, con algunas especialidades, atinentes al hecho de que, como se ha dicho, aquí solo pueden presentar proposiciones los empresarios seleccionados por la Administración, previa solitud de los mismos. Por ello, el Pliego de Cláusulas Administrativas tenía que fijar el número de las invitaciones (entre 5 y 20) y los criterios objetivos de selección. La forma y contenido de las mismas vino regulado en el art. 91 del Real Decreto 1098/2001, de 12 de octubre, «por el que se aprueba el Reglamento general de la Ley de Contratos de las Administraciones Públicas» (7).

No pretendemos analizar aquí las diferentes formulaciones que ha tenido a lo largo de una legislación tan cambiante. Para abreviar, diremos que la nueva Ley mantiene la sistemática de su antecedente inmediato: arts. 162 a 168 del Real Decreto Legislativo 3/2011, de 14 de noviembre, "por el que se aprueba el texto refundido de la Ley de Contratos del Sector Público" (TRLCSP), que introdujo un mayor detalle, aunque no cambios sustantivos(8). Por lo que, en lugar de resumirla,

(7) Un estudio del procedimiento restringido en esta etapa, en el libro de MORENO MOLINA, J.A. y PLEITE GUADAMILLAS, F. (2003), Nuevo régimen de contratación administrativo, La Ley, Madrid, págs. 408 y ss.

(8) CARBONERO GALLARDO, J.M. (2010), op. cit., pág. 487, destaca además la reiteración de principios, como la prohibición de la negociación de los términos del contrato con los solicitantes o candidatos o que su selección seguirá criterios objetivos y no discriminatorios, que expresan la preocupación por la limpieza del procedimiento, como el resto de la Ley. 
será más interesante reseñar los posibles cambios entre el anterior y el actual procedimiento restringido. Vaya por delante que las variaciones son pocas y está por ver si con ellas el procedimiento restringido pasa a ser más utilizado en la práctica (9).

Otro dato importante a tener en cuenta es que algunas disposiciones del procedimiento restringido sirven de base para los procedimientos con negociación (art. 169.2), diálogo competitivo (art. 174.2) y asociación para la innovación (art. 178.3 LCSP in fine).

\section{Características generales}

La nueva Ley dispone en su art. 131 que la adjudicación de los contratos se realizará, ordinariamente, utilizando el procedimiento abierto o el procedimiento restringido, como sucedía antes. Al ser un procedimiento ordinario, no se requiere una especial justificación, puesto que no limita la concurrencia. A sensu contrario, el art. 63.3.a LCSP sí obliga a publicar en el perfil del contratante la justificación del procedimiento utilizado para la adjudicación cuando sea distinto del abierto o del restringido. En ese sentido, el órgano de contratación mantiene, con carácter general, la facultad de optar por uno u otro (10), pero con una importante salvedad. $Y$ es que, como novedad, los contratos de concesión de servicios especiales listados en el Anexo IV (servicios de carácter social, sanitario, educativo, investigación, seguridad y un largo etcétera) se adjudicarán siempre mediante el procedimiento res-

(9) Como señalan interventores expertos en la materia, este era un procedimiento muy poco utilizado. En su opinión, porque no había equivalencia entre la complejidad de su gestión y los resultados que se obtenidos, que podían ser fácilmente alcanzados a través de un procedimiento abierto. CANALES GIL, A.Y HUERTA BARAJAS, J.A. (2010), La Contratación del Sector Público tras las reformas de 2010, Editorial Reus, Madrid, pág. 304. A pesar de sus elogiadas posibilidades, CARBONERO GALLARDO, J.M. (2010), pág. 327, conviene que el procedimiento restringido en la práctica se dilata más que el abierto y aumenta notablemente los trámites, lo que disuade habitualmente a la Administraciones de usarlo. De hecho, según la información estadística del Registro Público de Contratos del Ministerio de Hacienda, en 2016 fueron solo 7 los procedimientos restringidos, seguidos en el ámbito de la $A G E$, sobre un total superior a 11.000, mientras que las CCA tramitaron 41, sobre un total superior a 83.000 licitaciones.

http://www.minhafp.gob.es/es-ES/Areas\%20Tematicas/Contratacion/junta\%20consultiva\%20de\%20 contratacion\%20administrativa/paginas/registro\%20publico\%20de\%20contratos.aspx

(10) En ese sentido, la STSJ de Castilla-La Mancha n. ${ }^{\circ} 76 / 2009$, de 27 febrero (recurso 741/2005), relativa a un contrato para la aplicación aérea de productos fitosanitarios contra la mosca del olivo en 2005, señala que la elección del procedimiento restringido queda únicamente condicionada para la Administración a que previamente, en el anuncio de licitación, el órgano de contratación haya establecido los criterios objetivos de solvencia con arreglo a los cuales serán elegidos los candidatos que serán invitados a presentar proposiciones: «sin que aparezca como obligada la explicación de por qué en un determinado ejercicio se optó por el procedimiento restringido, si se cumplía con las condiciones propias de éste, como era el caso". 
tringido(11). Además la Ley considera especialmente adecuado este procedimiento cuando se trata de servicios intelectuales de especial complejidad, como algunos servicios de consultoría, arquitectura o ingeniería (art. 160.4 LCSP). Es decir, aunque no lo impone, recomienda el procedimiento restringido para ciertos contratos, dando un expreso respaldo que legitimaría prima facie su utilización en esos casos.

En el procedimiento restringido, ya se ha dicho, cualquier empresa interesada podrá presentar una solicitud de participación en respuesta a una convocatoria de licitación. Pero sólo podrán presentar proposiciones aquellos empresarios que, a su solicitud y en atención a su solvencia, sean seleccionados por el órgano de contratación. La Ley en esto no ha cambiado. Reitera igualmente que en este procedimiento está prohibida toda negociación de los términos del contrato con los solicitantes o candidatos (12).

Otra nueva previsión de la Ley para el procedimiento restringido es que, en contratos de servicios cuya presentación implique la realización de determinados desarrollos, los pliegos de cláusulas administrativas particulares puedan contemplar primas o compensaciones por los gastos en que incurran los licitadores al presentar su oferta. En el TRLCSP (2011), estas primas o compensaciones solo estaban contempladas para los participantes en los procedimientos de diálogo competitivo y en los concursos de proyectos (arts. 179 y 184 respectivamente)(13).

(11) Además de una descripción, en el Anexo IV estos contratos vienen identificados por un código CPV (Common Procurement Vocabulary - Vocabulario Común de Contratación Pública), que consta de hasta 9 dígitos, que van dando lugar a divisiones, grupos, clases y categorías. Este sistema permite identificar y categorizar todas las actividades económicas susceptibles de ser contratadas mediante licitación pública en la Unión Europea. Es similar a la nomenclatura española del CNAE que, aunque no aplica a licitaciones, es una forma de catalogar todas las actividades económicas. La principal utilidad de un código CPV es que permite identificar licitaciones y adjudicaciones en cualquier país de la Unión Europea sin necesidad de traducciones, que a veces pueden resultar imprecisas. Véase el Reglamento (CE) n. ${ }^{\circ}$ 2195/2002, de 5 de noviembre, del Parlamento Europeo y del Consejo, "por el que se aprueba el Vocabulario común de contratos públicos (CPV)». Véase RUIZ DE CASTANEDA, A. (2011), "La nomenclatura CPV en la contratación», en el libro Estudios en Homenaje a Angel Ballesteros, La Ley, Madrid.

(12) Un ejemplo real de este tipo de prácticas prohibidas, que en este caso intentaban ocultarse mediante empresas interpuestas, en la información publicada en El País por Óscar LOPEZ FONSECA, "Los seis pasos para amañar una adjudicación de 61 millones. Un informe de la UCO recién incorporado al sumario del "caso Púnica" detalla los pasos que siguió la trama para hacerse con un contrato del Ayuntamiento de Valdemoro". https://politica.elpais.com/politica/2017/03/13/ actualidad/1489418866_942289.html

Son muchas las propuestas formuladas desde la academia contra esta lacra. Por todos, véase GIMENO FELIU, J.M. (2014), "Reglas para la prevención de la corrupción en la contratación pública». Texto ponencia V Seminario de contratación pública, Formigal (Huesca).

(13) Con ello se trata de hacerlo más atractivo para los licitadores y ampliar su utilización por las Administraciones, según Isabel GALLEGO CÓRCOLES, en "Los procedimientos abierto, restringido, licitación con negociación, negociado sin publicidad y diálogo competitivo", del libro Estudio sistemático de la Ley de Contratos del Sector Público, dir. GIMENO FELIU, Aranzadi, 2018, pág. 1106. 


\section{Las solicitudes de participación}

\section{Plazo de presentación}

La especialidad fundamental del procedimiento restringido reside en la fase de selección de empresas candidatas. La Ley marca cuáles deben ser los plazos mínimos para que éstas puedan presentar su solicitud de participación y qué documentación tienen que adjuntar (art. 161 LCSP).

A diferencia delTRLCSP, estos plazos no distinguen según el objeto del contrato, aunque sí atienden a su carácter armonizado o no y, en su caso, urgente. En concreto, los plazos de presentación de las solicitudes de participación son los siguientes:

a) En primer lugar, si se trata de contratos no sujetos a regulación armonizada, el plazo para la presentación de solicitudes de participación será, como mínimo, de quince días, contados desde la publicación del anuncio de licitación en el perfil oficial correspondiente.

b) En segundo lugar, para los procedimientos de adjudicación de contratos sujetos a regulación armonizada la LCSP sienta, como criterio material, que el plazo de presentación deberá ser el suficiente para el adecuado examen de los pliegos y de las circunstancias y condiciones relevantes para la ejecución del contrato, todo ello en atención al alcance y complejidad del contrato. En cualquier caso, prescribe la Ley que no podrá ser inferior a treinta días, contados a partir de la fecha del envío del anuncio de licitación a la Oficina de Publicaciones de la Unión Europea.

c) En cambio, cuando se trate de contratos de obras, suministros y servicios sujetos a regulación armonizada, pero en los que el plazo general de presentación de solicitudes sea impracticable por una situación de urgencia (que, según el art. 119 LCSP, se refiere a contratos cuya celebración responde a una necesidad inaplazable o cuya adjudicación es preciso acelerar por razones de interés público), el órgano de contratación podrá fijar otro plazo que no será inferior a quince días contados desde la fecha del envío del anuncio de licitación.

Esta peculiar forma de fijar el dies a quo para este plazo se explica porque, conforme al Derecho europeo, para los contratos armonizados el art. 135 LCSP requiere que el envío al DOUE sea previo al anuncio en el perfil del contratante y, en su caso, en boletín oficial español, que debe dar ya cuenta de esa publicación.

Además de la obligación de anunciar la licitación en primer lugar en el DOUE, en todos los procedimientos restringidos el anuncio se 
debe publicar en el perfil del contratante, con una antelación mínima equivalente al plazo fijado para la presentación de las solicitudes de participación. Como es sabido, ahora es el perfil del contratante el instrumento fundamental para dar publicidad a la contratación pública (art. 63), que además debe estar alojado en la Plataforma de Contratación del Sector Pública, constituyendo un vicio de nulidad la falta de publicación del anuncio de licitación en el medio preceptivo (art. 39.2.c). La celeridad del procedimiento por acortamiento de los plazos derivado de la normativa europea se incrementa además por efecto de los medios digitales.

\section{Documentación a adjuntar}

Por su parte, las solicitudes de participación deberán ir acompañadas de la documentación acreditativa del cumplimiento de los requisitos previos(14), prevista en el art. 140 LCSP, salvo el documento acreditativo de la constitución de la garantía provisional:

a) La declaración responsable ajustada al formulario normalizado europeo de contratación, firmada y con identificación, en la que el licitador ponga de manifiesto que la sociedad está válidamente constituida, que el firmante ostenta la debida representación, que está clasificada o cumple los requisitos de solvencia económica, financiera y técnica o profesional exigido en el pliego, que no incurre en prohibición de contratar, una dirección de correo electrónico para notificaciones, etc.

b) Adicionalmente, la declaración pondrá de manifiesto que se cumple con los requisitos objetivos de solvencia que se hayan establecido para la selección de candidatos en el pliego, de acuerdo con el artículo 162 LCSP.

c) En los casos en que el empresario recurra a la solvencia y medios de otras empresas de conformidad (art. 75 LSCP), cada una de ellas también deberá presentar una declaración responsable. Lo mismo si varias empresas concurren agrupadas en una unión temporal,

(14) Sabido es que tanto los órganos administrativos como los tribunales resuelven esta cuestión de modo extremadamente formalista, aunque afecte a un incumplimiento en apariencia nimio. Así sucede en la STSJ el País Vasco n. ${ }^{\circ}$ 428/2002, de 3 mayo (recurso 73/1997), relativa a un concurso restringido para la adjudicación del servicio de defensa jurídica del Ayuntamiento, en la que se excluye a un licitador porque la declaración jurada de no incurrir en causas de incompatibilidad y los certificados de estar al corriente de las obligaciones fiscales y de Seguridad Social, aportados en el periodo de subsanación concedido por la mesa de contratación, eran de fecha posterior al momento en que finalizaba el plazo para la presentación de las solicitudes de participación. 
así como el compromiso de constituirla si el contrato fuera adjudicado a su favor (art. 69 LCSP).

f) Las empresas extranjeras, en los casos en que el contrato vaya a ejecutarse en España, deberán aportar una declaración de sometimiento a los tribunales españoles de cualquier orden, para todas las incidencias que pudieran surgir del contrato, con renuncia al fuero jurisdiccional que pudiera corresponder al licitante.

g) Cuando el pliego prevea la división en lotes del objeto del contrato, si los requisitos de solvencia económica y financiera o técnica y profesional exigidos variaran de un lote a otro, se aportará una declaración responsable por cada lote o grupo de lotes al que se apliquen los mismos requisitos de solvencia.

h) Cuando el Pliego de Cláusulas Administrativas Particulares o el documento descriptivo exijan la acreditación de otras circunstancias distintas de las que comprende el antedicho formulario europeo, deberán indicar la forma de su acreditación.

Finalmente, no será necesaria la presentación de documentos justificativos de los datos del empresario que consten en el Registro Oficial de Licitadores y Empresas Clasificadas del Sector Público o en una base de datos nacional de un Estado miembro, como un expediente virtual de la empresa, un sistema de almacenamiento electrónico de documentos o un sistema de precalificación, siempre que sean accesibles de modo gratuito para la mesa y el órgano de contratación.

En este punto merece la pena resaltar como novedad la sustitución de certificados y copias compulsadas por declaraciones responsables, por imperativo del art. 59 Directiva 2014/24/UE, de 26 de febrero de 2014, "sobre contratación pública, según un formulario normalizado europeo además(15).

\section{Selección de los candidatos}

\section{Criterios objetivos de solvencia}

Es preceptivo que, antes de anunciar la licitación, el órgano de contratación haya establecido los criterios objetivos de solvencia, de entre los previstos en los arts. 87 a 91 LCSP, con arreglo a los cuales se elegirán los candidatos que serán invitados a presentar proposiciones (art. 162.1 LCSP).

(15) Explica el profesor GIMENO FELIU, J.M. (2015), op. cit., que esto supone un ahorro de costes para todas las partes, que beneficia especialmente a las PYMES, si bien obliga a la posterior comprobación de la documentación que aporte el candidato propuesto de manera condicional, antes de convertirse en el licitador seleccionado y recibir la adjudicación. 
Esos criterios o normas, que deberán ser objetivos y no discriminatorios (16), han de figurar en el anuncio de licitación (17).

Estos criterios, recordemos, se refieren a la solvencia económica y financiera del empresario, que deberá acreditarse por uno o varios de los medios elegidos por el órgano contratante: volumen anual de negocios, seguro de responsabilidad civil por riesgos profesionales, patrimonio neto, ratio entre activos y pasivos, etc. Una elección discrecional que, en cualquier caso, conviene motivar(18). En los contratos de obras, la solvencia técnica se acreditará igualmente con las obras ejecutadas en los cinco últimos años, personal técnico disponible para la ejecución, títulos académicos y profesionales del empresario, los directivos y del responsable de la obra, plantilla media anual de la empresa, maquinaria, material y equipo técnico del que se dispondrá para la ejecución de las obras, etc. (19) En los contratos de suministro, mediante una relación de princi-

(16) La STS de 12 de enero de 2001 (rec. Casación 6984/1996) confirma la delTSJ de Andalucía, que había anulado los criterios y baremos previstos en el apartado de solvencia técnica de una contratación por el procedimiento restringido de una consultoría de apoyo técnico integrado a los servicios de carreteras provinciales, por vulneración del derecho fundamental de igualdad (art. $14 \mathrm{CE}$ ), al establecerse un baremo de puntuación desproporcionado, basado en el arraigo o radicación territorial, lo que produce la discriminación de las empresas aspirantes en las que no concurra el factor de radicación geográfica.

(17) Al respecto, la ya citada la STJCE (Sala Sexta) de 12 de diciembre de 2002 (asunto C-470/99), dictaminó: "La Directiva 93/37 debe interpretarse en el sentido de que, si, en el marco de un procedimiento restringido, la entidad adjudicadora ha fijado previamente las reglas de ponderación de los criterios de selección de los candidatos que serán invitados a presentar una oferta, está obligada a indicarlos en el anuncio o en los documentos de la licitación.»

(18) La STSJ de Cataluña n. ${ }^{\circ} 772 / 2004$, de 4 junio (recurso 67/2001), anula la convocatoria, la adjudicación y la contratación de un concurso, mediante procedimiento restringido, para la contratación de consultoría y asistencia técnica, de redacción del proyecto de rehabilitación y dirección de obras de un antiguo edificio municipal, al considerar ilegal, entre otras, una cláusula de los pliegos de condiciones administrativas que establecía como único medio para acreditar la solvencia económica y financiera de los licitadores un informe de instituciones financieras o de auditoria, excluyendo sin razón alguna el resto de medios previstos en el art. 16 LCAP.

(19) Como antes se dijo, estas especificaciones no pueden basarse en criterios discriminatorios. La STSJ de Andalucía (Sevilla) de 23 mayo 2006 (recurso 140/2003), examina la contratación por el procedimiento restringido en forma de concurso de diversas obras de restauración forestal y tratamientos silvícolas. Para poder participar, en el pliego de condiciones administrativas particulares se establece un umbral de experiencia en obras públicas o privadas análogas, que se puntúa mediante la siguiente fórmula, trascrita en la Sentencia: «I=4(A1+3A2)/PLS IVA, siendo: I puntuación que corresponde a cada empresa; AI Volumen acreditado de obras similares realizadas fuera de Andalucía en miles de euros IVA excluido; A2 Volumen acreditado de obras similares realizadas en Andalucía en miles de euros IVA excluido; y PLSIVA presupuesto de licitación en miles de euros IVA excluido". Según elTribunal: "A la vista de dicha cláusula se observa, que la fórmula empleada favorece y puntúa tres veces más los trabajos realizados dentro de la Comunidad Autónoma de Andalucía frente a los realizados en otras Comunidades Autónomas. Dicha diferenciación en el trato, ha de reputarse discriminatoria, por carecer de fundamento objetivo y razonable, y ello es así por cuanto difícilmente puede justificarse la singularidad de las obras ejecutadas dentro del territorio de una determinada Administración Pública, frente a obras análogas desarrolladas en otro territorio, cuando no se ha motivado la existencia de unas particularidades propias y exclusivas de dicho territorio frente al resto. En este sentido, el TJCE en su sentencia de 16 de septiembre de 1999 (cuestión prejudicial 
pales suministros realizados en los últimos tres años de igual o similar naturaleza que los que constituyen el objeto del contrato, personal técnico e instalaciones o medios de los que se disponga para la ejecución del contrato, etc. En los contratos de servicios, la solvencia técnica o profesional de los empresarios deberá apreciarse teniendo en cuenta sus conocimientos técnicos, eficacia, experiencia y fiabilidad, lo que deberá acreditarse, según el objeto del contrato, mediante una relación de los principales servicios o trabajos realizados de igual o similar naturaleza que los que constituyen el objeto del contrato, la maquinaria, material y equipo técnico del que se dispondrá para los trabajos o prestaciones, etc. Esos mismos medios servirán para acreditar la solvencia profesional o técnica en contratos distintos de los de obras, servicios o suministro.

Es evidente que estos criterios específicos pueden resultar discutibles y su valoración jurídica difícil de prejuzgar fuera del caso concreto, de modo que éstos pueden pasar el filtro de los tribunales si la Administración da una justificación creíble que la recurrente no sea capaz de desvirtuar(20).

Es importe también recordar que la concreción de los requisitos mínimos exigidos para un contrato y de los medios admitidos para acreditarlos debe establecerse por el órgano de contratación en los pliegos, concretando las magnitudes, parámetros o ratios y los umbrales o rangos de valores que determinarán la admisión o exclusión de los licitadores o candidatos, sin perjuicio, repetimos, de indicarlo igualmente en el anuncio de licitación o en la invitación a participar. En su defecto, serán de aplicación los establecidos en los artículos 87 a 90 para el tipo de contra-

suscitada por Austria) descarta toda discriminación de los contratistas, considerando contrario a ese principio el favorecimiento de «empresas establecidas en determinadas regiones del territorio nacional», comportando tales discriminaciones una vulneración u obstáculo a la libre concurrencia; esto es, resulta del todo contrario al principio de igualdad el favorecimiento de una determinada región. Por todo ello, se declara la nulidad de pleno derecho de la cláusula 7 impugnada considerada contrarios al principio de igualdad y discriminatoria.»

(20) Por ejemplo, la ya citada STSJ de Castilla-La Mancha n. ${ }^{\circ} 76 / 2009$, de 27 febrero (recurso $741 / 2005)$ valora correctamente como criterio de selección de las empresas invitadas el conocimiento del territorio por parte de los pilotos de las avionetas, acreditado por certificados de trabajos anteriores para la Administración, dada la complejidad y peculiaridad del servicio sanitario a prestar, motivado por la evitación del riesgo de siniestros y la optimización de recursos si se conoce la orografía del terreno donde se va a trabajar. La SAN de 2 de noviembre de 2000 (recurso 570/1999), relativa a un contrato de asistencia técnica para la redacción de un proyecto de rehabilitación de un edificio, por el procedimiento de concurso restringido, no aprecia que sea contrario al art. 92 LCAP valorar positivamente para ser invitado el haber realizado intervenciones en el mismo inmueble: «en la medida en que la propia ley permite una limitación, a efectos de la selección para invitar al número de licitadores previamente fijado, puede, en esta fase de selección, tenerse en cuenta una mayor cualificación específica, que se deduciría de un conocimiento previo de la obra, sin que pueda aducirse que ello es contrario al principio de concurrencia, por cuanto sería tanto como aceptar que el procedimiento restringido va contra dicho principio, lo que no tiene ningún fundamento legal. Otra cosa distinta es que a efectos de la adjudicación, solo se considere la propuesta económica y la adaptación de la solución al programa establecido.» 
tos correspondiente, que tendrán igualmente carácter supletorio para los no concretados en los pliegos (21).

Por otro lado, hay que tener presente que la clasificación del empresario en un determinado grupo, subgrupo y categoría puede servir de prueba bastante que le exima de aportar nueva documentación, a cuyo efecto en el anuncio o invitación deberá indicarse el código CPV.

Aparte, esta exigencia de acreditación de la solvencia económica y financiera o de la solvencia técnica o profesional puede suprimirse reglamentariamente para los contratos cuyo importe no supere un determinado umbral.

\section{Número de empresarios a invitar}

Otro extremo que tendrá que fijar el órgano de contratación es una horquilla con el número mínimo y, en su caso, máximo de empresarios a los que invitará a participar en el procedimiento. La Ley establece que el número de candidatos invitados debe ser suficiente para garantizar una competencia efectiva y no pone un número máximo, pero sí un mínimo, que no podrá ser inferior a cinco (art. 162.2 LCSP) (22). El número debe figurar en el anuncio de licitación.

Puede ocurrir que, una vez escrutadas las solicitudes, el número de candidatos que cumplan los criterios de selección sea inferior a ese número mínimo, en cuyo caso el órgano de contratación podrá continuar el procedimiento con los que reúnan las condiciones exigidas(23), pero no podrá invitar a empresarios que no hayan solicitado participar en el mismo ni a candidatos que no cumplan las condiciones.

(21) Una previsión en ese sentido fue introducida como art. 79.bis TRLCSP por la DF 3.5 de la Ley 25/2013, de 27 diciembre. Antes, el Informe de la JCCAE n. ${ }^{\circ} 63 / 08$, de 31 de marzo de 2009, había recomendado la fijación en el pliego de cláusulas administrativas particulares de algún método para valorar la solvencia técnica y profesional de los candidatos, sin generar discriminación ni trato preferencial, con el fin de poder descartar algunos si se superaba el número máximo de empresas a invitar.

(22) La STJCE de 26 de septiembre de 2000 (asunto C-225/98), en una demanda de la Comisión motivada por diversos procedimientos de adjudicación de contratos públicos de obras relativos a la construcción y el mantenimiento de edificios escolares por autoridades francesas, subraya esta exigencia: «Sin embargo, si el legislador comunitario ha considerado que, en el marco de un procedimiento restringido y cuando los órganos de contratación establecen límites, un número de candidatos inferior a cinco no es suficiente para garantizar una competencia real, lo mismo debe afirmarse, con mayor razón, en caso de que los órganos de contratación opten por un número máximo de candidatos a los que invitar.»

(23) Es lo que sostiene la STSJ de Castilla-La Mancha 76/2009, de 27 febrero (recurso 741/2005), antes citada: "Como tampoco asumimos la mencionada - mas no probada- desviación de poder, por vulneración del art. 91.1.b) de la Ley de Contratos a la sazón vigente, al haber sido el número de empresas invitadas al concurso inferior a cinco. Sin embargo, de ese precepto se desprende que es en el anuncio de la convocatoria donde la Administración ha de proyectar su previsión, ciertamente entre cinco y veinte empresas, y en el caso que nos ocupa se preveía que fueran diez; pero ello no implica que en la fase posterior tuvieran que ser también más de cinco las empresas seleccionadas;...» 
De la Ley entendemos que, si los pliegos no fijan un número máximo de candidatos a seleccionar, no cabe que la mesa o el órgano de contratación excluyan a candidatos que sí cumplen los criterios de solvencia ¿Con qué criterio se les denegaría la invitación? Para que el procedimiento restringido permita limitar el número de los ofertantes que pueden presentarse a la fase de adjudicación y las proposiciones que la Administración ha de estudiar resulta indispensable, por tanto, fijar en los pliegos un número máximo que, como ya se ha dicho, no podrá ser inferior a cinco. Acompañarlo de un baremo o método de ponderación que permita ordenarlos de mejor a peor facilitaría notablemente la motivación de la selección por parte del órgano de contratación, lo que deberá constar en el pliego o en el anuncio(24).

\section{Examen e invitación de los candidatos}

El siguiente paso a dar por el órgano de contratación será comprobar la personalidad y solvencia de los solicitantes, para seleccionar a los que deban pasar a la siguiente fase (art. 162.4 LCP). Esta selección ha de hacerse aplicando los criterios establecidos, de modo que todos los seleccionados los cumplan. Si fueran más del número máximo previsto, tendrá que escoger a los que obtengan una mejor puntuación, pues no cabe a nuestro juicio que esa elección se haga de modo discrecional, aleatorio o arbitrario. Dicho de otro modo, no parece de recibo que el órgano de contratación pueda excluir motu proprio a empresas que cumplan los criterios sentados en los pliegos mientras no se alcance el número máximo previamente establecido, sea cinco u otro superior.

Hecha la selección, el órgano de contratación procederá a invitar simultáneamente y por escrito a todas las empresas para que presenten sus proposiciones dentro del plazo que veremos más adelante.

\section{Contenido de la invitación}

Como se ha dicho, la invitación a las empresas escogidas tendrá que realizarse por escrito y simultáneamente. Lógico es pensar que a través de un medio fehaciente y válido en Derecho. En ese sentido, se impone la

(24) Al respecto, la STJCE (Sala Sexta) de 12 de diciembre de 2002, en el asunto C-470/99, en una cuestión prejudicial elevada por un tribunal austriaco, a propósito un procedimiento de adjudicación de un contrato público de obras, dictaminó "La Directiva 93/37 debe interpretarse en el sentido de que, si, en el marco de un procedimiento restringido, la entidad adjudicadora ha fijado previamente las reglas de ponderación de los criterios de selección de los candidatos que serán invitados a presentar una oferta, está obligada a indicarlos en el anuncio o en los documentos de la licitación.» 
notificación personal, sin perjuicio de otro tipo de publicaciones en boletines, perfiles o tablones de anuncios.

Con arreglo al art. 163 LCSP, las invitaciones han de tener este contenido:

a) Una referencia al anuncio de licitación publicado.

b) La fecha límite para la recepción de ofertas.

c) La dirección a la que deban enviarse

d) La lengua o lenguas en que deban estar redactadas.

e) Los documentos que se deban adjuntar complementariamente.

f) Los criterios de adjudicación del contrato y su ponderación relativa o, en su caso, el orden decreciente de importancia atribuido a los mismos, si no figurasen en el anuncio de licitación.

g) El lugar, día y hora de la apertura de proposiciones.

h) Las indicaciones para permitir el acceso por medios electrónicos a los pliegos y demás documentación complementaria.

i) La forma, lugar, fecha e importe a pagar por los pliegos y demás documentación complementaria que fuera accesible por medios no electrónicos, en los casos en que está admitido legalmente (circunstancias técnicas, confidencialidad y seguridad del art. 138.2 LCSP)

\section{Plazo de presentación de proposiciones}

Por lo que hace al plazo de presentación de las proposiciones, el art. 164 LCSP atiende al carácter armonizado o no y, en su caso, urgente:

a) En los relativos a contratos no sujetos a regulación armonizada, el plazo no será inferior a diez días, contados desde la fecha de envío de la invitación.

b) Para los sujetos a regulación armonizada será el suficiente para la adecuada elaboración de las proposiciones en función del alcance y complejidad del contrato, que no será inferior a treinta días, contados a partir de la fecha de envío de la invitación escrita. Este plazo podrá reducirse en estos casos:

- Si se hubiese enviado el anuncio de información previa con la antelación y toda la documentación necesaria que prevé el art. 156.3.a LCSP, el plazo general podrá reducirse a diez días.

- Cuando el plazo general sea impracticable por tratarse de una situación de urgencia, en los términos antes descritos, el órgano de contratación podrá fijar otro plazo que no será inferior a diez días contados desde la fecha del envío de la invitación escrita. 
- Si el órgano de contratación aceptara la presentación de ofertas por medios electrónicos, podrá reducirse el plazo en cinco días. De los tres supuestos, esta será la única reducción aplicable en las concesiones de obras y de servicios.

No deja de ser llamativa, a mi juicio, esta peculiar determinación del dies a quo para el cómputo de un plazo tan esencial como es el de presentación de ofertas, puesto que así el tiempo que medie entre el envío y la recepción de la invitación por el destinatario juega en su contra, lo que perjudica claramente a las empresas no avisadas y no favorece la igualdad de oportunidades para competir. En mi opinión, la influencia del Derecho de la Unión Europea (negativa en este caso) no justifica que se excepcione la regla general del procedimiento administrativo común, por la que los plazos se cuentan a partir de la publicación o de la recepción de la notificación por el destinatario (art. 30.3 LPAC), y no desde el envío de esta (25). Por muy perfectos que sean los sistemas de comunicación, ninguno es infalible. Al computar como fecha de inicio del plazo la del envío de la invitación, se trasladaría al interesado la carga de probar cualquier pérdida o demora que no le sea imputable, a costa de su seguridad jurídica. La posición ordinamental de la LPAC, que asegura la igualdad de trato de todos los ciudadanos ante las Administraciones Públicas, debería prevalecer para salvaguardar esta elemental garantía.

\section{Adjudicación}

El procedimiento restringido termina aquí su peculiaridad, puesto que la fase de adjudicación del contrato se remite a lo previsto en la Ley para el procedimiento abierto, sin que sea necesario calificar nuevamente la documentación acreditativa del cumplimiento de los requisitos previos, puesto que ya se hizo antes de cursar las invitaciones (art. 165 LCSP) (26). Ahora también podrá emplearse la subasta electrónica, siempre que las

(25) Esta incorrección viene siendo denunciada por la doctrina con motivo de similares regulaciones anteriores. En ese sentido, el profesor Antonio FORTES señala que desde el envío hasta la recepción pueden trascurrir días sin que el candidato seleccionado pueda conocer la invitación y, consiguientemente, empezar a preparar su oferta; y también puede ocurrir que la invitación le llegue cuando el plazo de recepción haya terminado o que nunca llegue a su destinatario, lo que a nuestro juicio supone una patente desigualdad de trato y una indefensión. FONTES MARTíN, A. (2009), tomo II del libro colectivo Comentarios a la Ley de Contratos del Sector Público, Bosch, Barcelona, pág. 1482, que cita la opinión en el igual sentido de IRURZUN MONTORO, F. (1997), "De la adjudicación de los contratos", en VV.AA. Comentarios a la Ley de contratos de las Administraciones Públicas, Madrid, 1997, pág. 335.

(26) La ya citada STSJ de Cataluña n. ${ }^{\circ} 772 / 2004$, de 4 junio (recurso 67/2001), considera ilegal y anula la cláusula del pliego que obligaba a los participantes seleccionados a volver a presentar la documentación aportada cuando concurrieron a la licitación, por infringir el art. 35.f LRJPAC. 
especificaciones del contrato puedan establecerse de manera precisa en los pliegos y que las prestaciones no tengan carácter intelectual, como los servicios de ingeniería, consultoría y arquitectura (art. 143.2 LCSP). EI examen de las proposiciones, la propuesta de adjudicación y demás actuaciones tendentes a la adjudicación siguen las mismas reglas que si fuera un procedimiento abierto; o una subasta electrónica, en su caso. Tampoco hay unos requisitos y criterios de adjudicación del contrato especiales por ser el procedimiento restringido(27). Lo que no significa que no tenga su peculiaridad; por ejemplo que, a diferencia del procedimiento abierto, si el concurso se tramitó por el procedimiento restringido los criterios objetivos que se utilizan para seleccionar a los participantes por su experiencia o especialización también pueden utilizarse para efectuar la adjudicación (28).

En principio, las empresas participantes no adjudicatarias no tienen derecho a percibir ninguna compensación por haber presentado su proposición (29), salvo que se hubiera previsto así en los pliegos(30).

(27) En la STSJ de Aragón n. ${ }^{\circ}$ 1022/2000, de 20 diciembre (recurso 1184/1996), cuyo objeto era el contrato de proyecto y ejecución de los trabajos de restauración de una ermita, por el procedimiento restringido mediante concurso, se examina con minuciosidad el decurso de las sucesivas fases de invitación y adjudicación, las funciones de la mesa y del órgano de contratación, que en este caso se ajustaron a Derecho.

(28) En el Informe de la JCCAE n. ${ }^{\circ}$ 13/98, de 30 junio 1998, se examina la procedencia de emplear como criterios objetivos de valoración de las proposiciones en los concursos los medios que se especifican para valorar la solvencia de las empresas y, en concreto, la experiencia de los suministradores, para llegar a esta conclusión: "1. Que según se desprende de las Directivas comunitarias sobre contratación pública y de la Ley de Contratos de las Administraciones Públicas, la experiencia es requisito que puede justificar la solvencia del empresario en la fase de verificación de su aptitud, pero no puede utilizarse como criterio de adjudicación del concurso incluido entre los enumerados en el artículo 87 de la citada Ley. 2. Que la conclusión anterior, que se considera incuestionable en el procedimiento abierto, no tiene aplicación, por su naturaleza específica, en el procedimiento negociado y debe ser objeto de matizaciones en relación con el procedimiento restringido, dado que entre los criterios objetivos a que se refiere el artículo 92.1.a) de la Ley de Contratos de las Administraciones Públicas, diferentes de los enumerados en el artículo 87, pueden incluirse, cuando las características del contrato a adjudicar lo aconsejen, los que hagan referencia a la experiencia o especialización de la empresa.» (la cursiva es nuestra)

(29) Este criterio viene de antiguo, como se expresa en la STS de 11 julio 1986 (RJ 1986/5064), referida a la solicitud por un ayuntamiento de oferta-presupuesto para la redacción de un anteproyecto de polideportivo a varias empresas: "aunque a efectos dialécticos se admitiese la conceptuación dada por el actor [concurso restringido de anteproyectos], no por ello habría de aceptarse la consecuencia de abono o pago del coste de los anteproyectos, ya que ante el silencio o falta de norma o cláusula expresa al efecto, la regla general es la contraria por cuanto sólo es aceptada en definitiva la oferta seleccionada (anteproyecto), haciéndola suya la Administración a través de la adjudicación definitiva o figura equivalente y sin que los demás ofertantes tengan, sin más, derecho al pago de sus trabajos, salvo que expresamente así lo estableciese la Administración, o bien en el caso de que hiciere suyos los estudios o anteproyectos presentados.»

(30) Es lo que reconoce la STSJ de Galicia n. ${ }^{\circ}$ 353/2010, de 31 de marzo (recurso 4531/2007), en su FJ $4 .^{\circ}$, relativa a un procedimiento restringido y modalidad de concurso para contratar la redacción del proyecto sectorial y proyecto básico de un nuevo hospital, cuyo pliego establecía una indemnización de $75.000 €$ por haber participado en el proceso selectivo. 
Dicho esto, lo que no parece estar bien resuelto por la jurisprudencia es la indemnización a la que tendría derecho la empresa recurrente cuando la contratación es anulada, sea porque resulta indebidamente excluida o no invitada sea por vicios en la fase de adjudicación. En algunos casos las sentencias únicamente conceden los gastos en que la empresa hubiera incurrido con motivo de la contratación(31), lo que creemos que no repara la injusticia sufrida. Resultan, a nuestro entender, más equitativas aquellas que reconocen una indemnización equivalente al lucro cesante del 6\% del precio del contrato, esto es, el beneficio industrial (32). Lo cual, a la postre, incentiva la buena administración y evita ámbitos de impunidad material.

\section{Bibliografía citada}

CANALES GIL, A. y HUERTA BARAJAS, J.A. (2010), La Contratación del Sector Público tras las reformas de 2010, Editorial Reus, Madrid.

CARBONERO GALLARDO, J.M., (2010), La adjudicación de los contratos públicos, La Ley, Madrid

FONTES MARTíN, A. (2009), tomo Il del libro colectivo Comentarios a la Ley de Contratos del Sector Público, Bosch, Barcelona.

GALLEGO CÓRCOLES, I. "La modificación de los contratos en la cuarta generación de directivas sobre contratación pública», $X$ Congreso, AEPDA, Aranzadi-Thomson, 2015.

GALLEGO CÓRCOLES, I. "Los procedimientos abierto, restringido, licitación con negociación, negociado sin publicidad y diálogo competitivo", en el libro Estudio sistemático de la Ley de Contratos del Sector Público, Aranzadi, 2018, págs. 1073 a 1493.

(31) La STSJ de Asturias n. ${ }^{\circ}$ 1061, de 27 junio 2005 (recurso 1182/2000) anula la no selección de una empresa en un procedimiento restringido, al entender que la misma había probado con informes periciales que no existen diferencias litológicas ni climáticas en los montes asturianos respecto de los castellano-leoneses a los que se referían las certificaciones aportadas; empero deniega indemnizar a la mercantil no invitada con el beneficio industrial del $6 \%$ del precio de las obras ofertadas, "ya que no es acogible dicha pretensión como lucro cesante, y ello porque el procedimiento de adjudicación ha sido el de la subasta, y según el artículo 74 de la Ley de Contratos de las Administraciones Públicas, la adjudicación, entre las seleccionadas, se debió de hacer a la que presentase la oferta más baja, y es lo cierto que tal circunstancia no ha podido verificarse al no ser admitida la recurrente a la licitación.». En consecuencia, dispone que la indemnización debe consistir únicamente en los gastos que justifique haber tenido.

(32) Así, en un concurso público, tramitado con urgencia por el procedimiento restringido para adjudicar el servicio de mensajería, al apreciar la comisión de un vicio de desigualdad en las actuaciones administrativas, la STSJ del País Vasco n. ${ }^{\circ}$ 735/2002, de 27 septiembre (recurso 1998/1998), reconoce una indemnización del $6 \%$ del precio del contrato como equivalente económico del derecho al procedimiento del que fue ilícitamente privada la empresa recurrente, a pesar de que la suya no era la mejor oferta. 
GARCIA DE ENTERRÍA, E. (1953), «Dos regulaciones orgánicas de la contratación administrativa», en $R A P \mathrm{n} .^{\circ} 10$.

GIMENO FELIU, J.M. (2015), "La reforma comunitaria en materia de contratos públicos y su incidencia en la legislación española. Una visión desde la perspectiva de la integridad", en libro Observatorio de los Contratos Públicos, número especial, Las Directivas de Contratación Pública, Aranzadi, Cizur Menor (Navarra).

GIMENO FELIU, J.M. (2014), "Reglas para la prevención de la corrupción en la contratación pública». Texto ponencia $V$ Seminario de contratación pública, Formigal (Huesca).

GIMENO FELIU, J.M. ${ }^{a}$ (2017), "La nueva Ley de Contratos del Sector Público: una ventana de oportunidad para recuperar el liderazgo institucional público con y desde la contratación pública», Observatorio de Contratación Pública, consulta 23-10-2017 (http://www.obcp.es/index.php/mod. opiniones/mem.detalle/id.317/relmenu.3/chk.5ae6d56c8ce0a3e6533497 d25a4135ff).

GONZÁLEZ GARCÍA, J. (2017), "Nueva Ley de Contratos del Sector Público», consulta 4-11-2017 (https://www.globalpoliticsandlaw.com/2017/11/04/ nueva-ley-contratos-sector-publico/).

MORENO MOLINA, J.A. y PLEITE GUADAMILLA, F. (2003), Nuevo régimen de contratación administrativo, 3 . $^{\mathrm{a}}$ ed., La Ley, Madrid.

ROMAR VILLAR, J.C. "Diferencias en la doctrina de los tribunales administrativos de recursos contractuales, en relación al recurso especial en materia de contratación", 20-1-2014, http://www.obcp.es/index.php/ mod.opiniones/mem.detalle/id.132/relcategoria.121/relmenu.3/chk. d269a259dba4a3fd84b08962cde4337b

RUIZ DE CASTANEDA, A. (2011), "La nomenclatura CPV en la contratación", en el libro colectivo Estudios en Homenaje a Ángel Ballesteros, La Ley, Madrid.

SANTIAGO FERNÁNDEZ, M.J., "LosTribunales administrativos de recursos contractuales como mecanismos de control en la contratación pública. Perspectiva actual y de futuro", en http://asocex.es/los-tribunales-administrativos-de-recursos-contractuales-como-mecanismos-de-controlen-la-contratacion-publica-perspectiva-actual-y-de-futuro;

Trabajo recibido el 1 de diciembre de 2017

Aceptado por el Consejo de Redacción el 16 de febrero de 2018 
LABURPENA: Lan honetan, Sektore Publikoko Kontratuei buruzko azaroaren 8ko 9/2017 Legean prozedura mugatua nola erregulatu den azaltzen da. Lege horrek, hain zuzen, Europako Parlamentuaren eta Kontseiluaren 2014ko otsailaren 26ko 2014/23/EB eta 2014/24/EB Zuzentarauen transposizioa egiten du Espainiako ordenamendu juridikora. Oro har, aurrekoaren (Sektore Publikoko Kontratuen Legearen testu bategina onartzen duen azaroaren 14ko 3/2011 Legegintzako Errege Dekretuaren) sistematikari eusten dio, baina, era berean, ezagutu beharko diren berritasun batzuk ematen ditu; hala nola, IV. eranskinean zerrendatuta dauden zerbitzu berezien emakida-kontratuak (gizarte-, osasun-, hezkuntza-, ikerketa- eta segurtasun-arloko zerbitzuenak, beste askoren artean) prozedura mugatuaren bidez esleitzeko eskakizuna. Legeak, bestalde, oso egokitzat jotzen du prozedura hori konplexutasun bereziko zerbitzu intelektualak (aholkularitza-, arkitektura- edo ingeniaritza-zerbitzu batzuk, adibidez) tartean daudenerako; hortaz, ezarri ere ezartzen ez badu ere, prozedura mugatua gomendatzen du kontratu jakin batzuetarako. Legean, prozedura mugaturako beste aurreikuspen bat dago: zerbitzu batzuk aurkeztean garapen jakin batzuk egin behar badira eta zerbitzu horiek kontratatu nahi badira, administrazio-klausula partikularren orriek hobariak edo konpentsazioak jaso ahalko dituzte, lizitatzaileek beren eskaintza aurkezteko orduan egin behar izan dituzten gastuak estaltzeko.

GAKO HITZAK: Administrazio Zuzenbidea Sektore publikoko kontratuak. Prozedura mugatua.

RESUMEN: En este trabajo se da cuenta de cómo ha quedado regulado el procedimiento restringido en la reciente Ley 9/2017, de 8 de noviembre, de Contratos del Sector Público, «por la que se transponen al ordenamiento jurídico español las Directivas del Parlamento Europeo y del Consejo 2014/23/UE y 2014/24/UE, de 26 de febrero de 2014». En general, mantiene la sistemática de su antecesor (Real Decreto Legislativo 3/2011, de 14 de noviembre, «por el que se aprueba el texto refundido de la Ley de Contratos del Sector Público»), pero también aporta algunas novedades que convendrá ir conociendo, como la exigencia de que los contratos de concesión de servicios especiales listados en el Anexo IV (servicios de carácter social, sanitario, educativo, investigación, seguridad y un largo etcétera) se adjudiquen siempre mediante el procedimiento restringido. Además la Ley considera especialmente adecuado este procedimiento cuando se trata de servicios intelectuales de especial complejidad, como algunos servicios de consultoría, arquitectura o ingeniería, por lo que, si bien no lo impone, recomienda el procedimiento restringido para ciertos contratos. Otra nueva previsión de la Ley para el procedimiento restringido es que, en contratos de servicios cuya presentación implique la realización de determinados desarrollos, los pliegos de cláusulas administrativas particulares puedan contemplar primas o compensaciones por los gastos en que incurran los licitadores al presentar su oferta.

PALABRAS CLAVE: Derecho administrativo. Contratos del sector público. Procedimiento restringido. 
ABSTRACT: This work gives account of how restricted procedure has been regulated by the recent Act 9/2017 of November $8^{\text {th }}$ of Public procurement contracts "that transposes European Parliament and Council Directives 2014/23/ UE and 2014/24/UE of February $26^{\text {th }}$ of 2014 to the Spanish legal system». In general, the previous system has remained (Legislative Royal-Decree 3/2011 of November $14^{\text {th }}$ "approving the revised text of the Act of Public procurement contracts") but it also has some novelties that we should know, for example the requirement that special service concession contracts listed in Annex IV (services of social, health, education, research or security nature and so on) were always to be awarded through the restricted procedure. Besides, the Act considers this procedure particularly suitable when it is about intellectual services with particular complexity, as for example some consulting, architecture and engineering services so even if it is not compulsory, the restricted procedure is recommended. Another new provision of this Act concerning the restricted procedure is that in service contracts where their submission implies some specific developments, the administrative clauses can grant premiums and compensations due to the expenses the bidders incur when they submit their tenders.

KEYWORDS: Administrative Law. Public procurement contracts. Restricted procedure. 